\title{
Human-elephant conflict: challenges in agriculture Sector in Polonnaruwa district; A study based on literature review
}

Sri Lanka Journal of Social Sciences and Humanities Volume 2 Issue 1, February 2021: 73-84 ISSN: 2773 692X (Online), 27736911 (Print) Copyright: (C) 2021 The Author(s)

Published by Faculty of Social Sciences and Languages, Sabaragamuwa University of Sri Lanka Website: https://www.sab.ac.lk/sljssh DOI: http://doi.org/10.4038/sljssh.v2i1.58

\author{
Fathima Sajla, J.S. ${ }^{1,}$ and Famees, M.F. ${ }^{2}$ \\ ${ }^{1}$ Department of Sociology, University of Colombo, Colombo, 00700, Sri Lanka. \\ ${ }^{2}$ Research Assistance, CEPA, Sri Lanka
}

Received: 27 July, 2021, Revised: 16 October, 2021, Accepted: 09 November, 2021.

How to Cite this Article: Fathima Sajla, J.S. \& Famees, M.F. (2022). Human-elephant conflict: challenges in agriculture Sector in Polonnaruwa district; A study based on literature review. Sri Lanka Journal of Social Sciences and Humanities, 2(1), 73-84.

\begin{abstract}
Human-elephant conflict is a major challenge to support the survivors and survival of elephants in tropical countries. Elephanthuman conflicts occur when it comes to farmland and chena plantations scattered over a large area. In addition, we can say that the elephant population has decreased significantly due to human-elephant conflicts in the last few decades. The North Central Province of Sri Lanka has been designated as a high-risk area with $42 \%$ incidents. This study is based on the Polonnaruwa district, to identify the nature of the human-elephant conflict. In addition, the current elephant-human conflict challenges in agriculture and farming and the search for causes of elephant deaths have been reviewed. Primary and secondary sources were used to systematically review the concepts of the elephant-human conflict and the identified features related to agriculture, farming, and the challenges faced by elephants. Causes of elephant-human conflict, crop damage, property damage, human death, and other damages have been discussed. The theme of the review is local measures taken by farmers to reduce conflicts, government measures low compensation methods for victims, use of bio fences, and use of electric fences. The elephant-human conflict has become a major socio-environmental issue in Sri Lanka. Although human-elephant conflict can be eliminated through inter-cooperation, methodological research has recommended the implementation of the challenges of minimizing human-elephant conflict in the Polonnaruwa district.
\end{abstract}

Keywords: C Human-Elephant conflict, farmers, Agriculture, Property, Elephant Mortality

\section{INTRODUCTION}

The global wild elephant is present in 50 countries. 130 which are in Asia and 37 in Africa. At the present, the number of wild Asian elephants is between $35,000-50,000$ while the number of captivity is around 10,000 (Burke, J; 2011). At present, human-Elephant conflict has highly increased nationally and globally. These conflict rates are increasing as the landscape continues to be transformed. Fewer amount resources are left for wildlife. Local communities are affected by these conflicts. Researchers have released/stated 160 elephants and 60 people die each year due to humanelephant conflict. As per the previous reports, the number of human death were 51 and injuries 33 from 2009 to 2010. The Number of property destruction is 752 . These conflicts are still growing in our country without a proper solution.

Globally, 15 African countries explore the physical and social factors that highly impact farmers' lifestyles due to humanelephant conflict. Sri Lanka boasts about elephant population and the elephants' population is more than 7500 . Although 80-100 human deaths are recorded early pawing at the human-elephant conflict. Statistic proves the most human deaths caused by wilder elephant attacks are taken place in Polonnaruwa, Eastern, Anuradhapura, southern, Northwestern, Uva wilder life zones (Shanmugaraja Vijayamohan, Rukmali; 2012).
Elephant conflict daily gambled with life and death. The Environmentalist's point of our Human-Elephant conflict has increased more in our society. Death and property damages are a much-rooted issue. This issue has created a considerable impact on the rural livelihood economy of Sri Lanka as well as the national economy (Gunatileke, N; 2008). Increasing human activities in forests and elephant survival is a major threat to elephants.

The Number of families' livelihoods are based on agricultural activities (DWC; 2006 -2007). Although many other social issues are arising through human-elephant conflicts, such as poverty. Poverty is caused by the destruction of harvest by wild elephants, which is an obstacle to national development and also has a negative impact on the education of the area where this issue exists.

The study was conducted to assess the extent of damage caused by elephants in the Polonnaruwa district. The main of this study is to explain the human-elephant conflict under the present context, how it negatively impacts farmers' livelihood and agriculture. Although the current issue has negatively impacted elephants and their population.

\footnotetext{
* Corresponding author: Tel.: +94 77111 2292; Email: sajlasadiq18@gmail.com

(iD) https://orcid.org/0000000208356242
} 


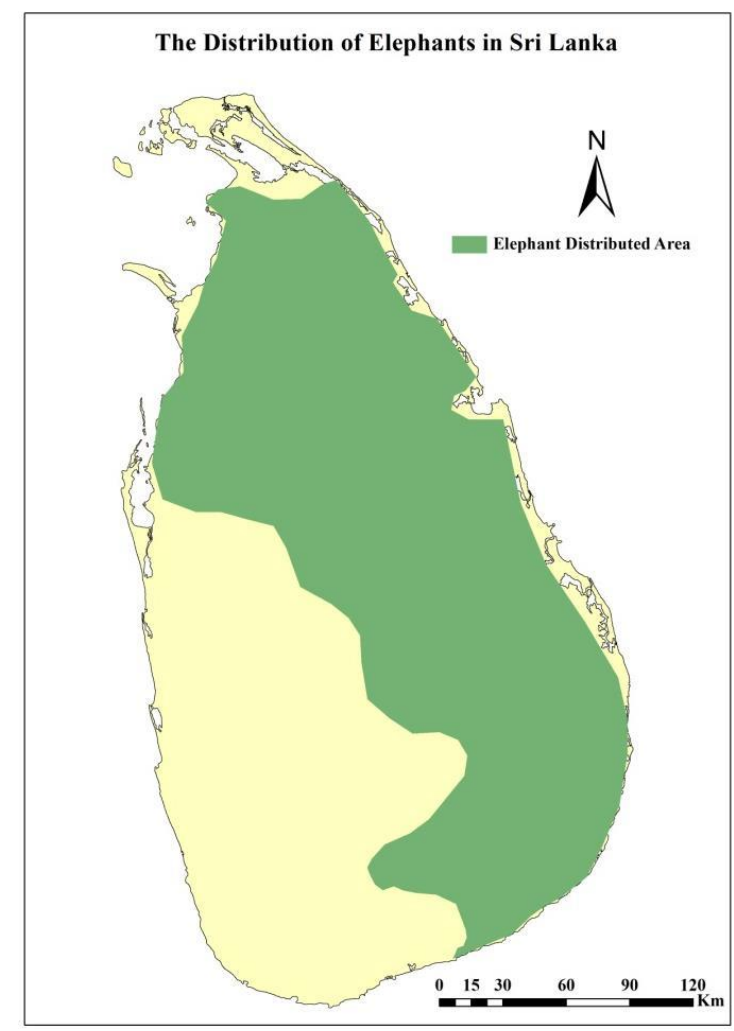

RESEARCH PROBLEM

Human elephant conflict as a manmade disaster in Sri Lanka

Sri Lanka has been facing natural and manmade disasters since ancient times. But there was no proper disaster management and mechanism for the country until tsunami accrued. Massive impacts on their livelihoods were damaged due to the Indian Ocean tsunami. The animal attack is one of the major disasters in Sri Lanka. But the animal attack will consider as a manmade disaster according to the meaning and the Act. we can prove the above fact by the statistic. In the period of 1950 to 2016, a minimum of 4200 persists in the wild animals with the conflict between men in Sri Lanka. 1464 elephants and humans were killed due to this problem within the last 12 years in Sri Lanka. (DWC; 2006 -2007).

The human-elephant conflict is one of the huge environmental and social-economic crisis in Sri Lanka. The conflict between humans and elephants has been an ongoing issue facing Sri Lanka's rural and urban areas. According to the wildlife conservation department estimate, 87 human deaths, 256 elephants' deaths, and over 800 property damage in 2018. (Alastair Nelson, Claudio Sillaro; 2003).

Although we can explore that Sri Lanka is one of the world's threatened biodiversity hot spots and is an important example of the struggle in developing nation hire with an explanation of their natural resources, at the cost of precious endemic fauna and flora as a habitat fragmentation occurs due to deforestation for plantations, agriculture, new development, small scale farming wild herds are increasingly venturing into the human settlement to find food. Conflict inevitably occurs, and as elephants continue destroying local people's crops, they were often killed. Historically, Sri Lanka had a deep connection with elephants. It is the animal that both revered culture and religion, but has now become a symbol of conflict in this fast-changing post-war development in the nation (Fernando et al., 2019).
This study was conducted to explore the current situation of human-elephant conflict and how it was negatively affecting farmers' livelihood and infrastructure/property as well as their life. Although exploring the sense of Elephant morality in Polonnaruwa district due to Human-Elephant conflict.

\section{LITERATURE REVIEW}

\section{Definitions of the concept.} Human-Elephant wildlife conflict.

"Human wildlife conflict in human goals and animals need as follows, human-wildlife conflict occurs when the needs and behaviour negatively affect humans goals." On the goals of humans or when the goals negatively impact the needs of wildlife.

The creator co-existence workshop at the 5 the annual words Pakistan United States Geological Survey defines human-wildlife conflict in two contexts. Firstly, actions by wildlife conflict with human goals, livelihood, and lifestyle. Secondly, human activities that threatened by safely and survived wildlife. However, both outcomes are decided by human responses (DWC; 2006 -2007).

"Human-wildlife simply but through the lens to damage property and interaction between wildlife and humans, which causes harm to the Human-wild animal or property. The property includes such as building, equipment, livestock, and pets.

The number of cases is extinct by decreasing population due to retaliatory killing. Although the human population is affected in terms of losses such as crop, property, injury, and also death.

Conflicts between people and wildlife are in a wide range all over the world. Consequences are such rats running rice harvest, elephants plowing up crops, trampling and damaging crops and fields. Universally on land, rivers and seas in the city as well as a country but, tend to be a specially marked in human settlements in forest- edge region. Agricultural production and an impediment to ruler developments wildlife depredations are an area of state concern and object of expert interventions (Gunatileke, N;2008).

Human-wildlife interactions may be positive with humans using resources from the wild for food, cloth, etc. Destroying and modifying the natural habitat of the wildlife damaging property cause injury or even death, these are negative aspects around human-wildlife conflict (Burke,j;2011).

Due to the increase of human population in forest cover of Sri Lanka has been re-closed rapidly because $20 \%$ forest is available out of $651,610 \mathrm{~km}$ Sri Lanka. Above $50 \%$ of forest cut for paddy and china cultivation, Human settlements. These are the main reasons for Human elephant conflict (Zimmerman; 2009, \& Dharamarathane; 2014).

\section{Causes for Human-Elephant conflict.}

Human elephant conflict is a major challenge for supporting the survival and persistence of elephants in their range countries. The main reason is sharing the development and wellbeing of human communities, sharing the space with mega-herbivorous as human transforms the landscape, forcing humans and elephants to live very closely. This was also the main cause for HEC, with often fatal outcomes. Sri Lanka annually estimates over 70 humans and 200 elephant moralities have been identified in conflict (Santi Pillai et al. 2020, Fernando and pastroni;2011).

Around 1.2 billion people, who live on 25 USD per day, live in Asian and African elephant range countries (Alon;1991). These countries also occurred human population growth of 
1-3\% per year in Asia and Africa. In some areas, marginalized communities increasingly compete with other societies, like elephants, for space and resources, low -income subsistence farmers often live near the forest with limited arable land, lack of irrigational access, and cultural ties. In addition, many rural communities move close to more permanent water sources for their household needs. Competition and scarce water sources during the dry periods to ensure stable water access will increase the risk of conflict between elephants and humans (Oshron;2004).

Studies illustrated in Zimbabwe suggest that the elephant population will co-exist to varying degrees with human communities until a threshold of about $15-20 \mathrm{~km}$. Furthermore, habitats loss and fragmentation occurred from 40 to $50 \%$ information of the landscape human livelihood activities were rendered the area until the elephants (Gunatilake, N; 2008). Habitat fragmentation fuels human-elephant conflict as potential as roads and farms surrounding fragmented feeding grounds are more conflict (Fernando et al.; 2005). Elephants are long-lived animals. The survival depends on their regular migration over large distances to find food, water social, and reproductive patterns. Elephants consume a maximum of 150 good forage and $190 \mathrm{~L}$ of water daily. It requires having a variety of grasses, shrubs, tree leaves, roots, and fruits. If they find more scarcity of food, they will come to the village to consume the water. These would be the main arguments for causes of HEC in South Asian countries and all over the world.

\section{The social dimension of human-elephant conflict}

Farmers throughout the world face trying to reduce or eradicate the impact of crop damage by wildlife on their standing crops. In Africa, dating back to their colonial time's crop depredation by elephants caused settlements to be displaced and food shortages. Some believe that human elephants conflict as old as agriculture in Africa (Wickramasinghe; 2017).

Sukumar (1989) has once pointed out that, especially for the elephants once used to crop-raiding and it became an optimal survival strategy (Silas et al.;1989). China elephants were responsible for large-scale crop and property damage which caused serious human-elephant conflicts in the region. A recent study on HEC in three districts of the northwestern wildlife region of Sri Lanka (Perera; 2007). Covering a land area of $11,000 \mathrm{~km}$ comprising around 1200 villages, which showed that there were over 1,000 elephants in the area.

The intensity of HEC in many rural areas adjacent to elephant habitats has been increasing rapidly. The form of the DWIC shows that 1369 elephants were killed during the past 10 years with gun shoot hardship and economic losses suffered by rural people may still have a positive attitude towards elephant conservation. Framers' attitudes to and opinions about elephants can be affected not only by the direct impact of human-elephant conflicts but by indirect factors as well (Burke, J;2011).

Colombo page, (2005) Found that people who practice agriculture been tolerant towards elephants than people who practice pastoralism. Farmer's attitudes can also differ depending on what type of crop they grow. Hedges \& Gunnery (2010) is mentioned that elephants often favour rice and watermelon, while they tend to field chili unpalatable. This study was conducted in the Baber district. This study of cropraiding was identified as the most common type of Humanwildlife conflict by men, women, and village leaders.

Elephant morality
Sri Lanka has ten to twenty percent of the Asian elephant population. An elephant needs to walk five kilometers to balance nature. According to the data current population of 3500 elephants requires around $17,500 \mathrm{~km}$ or $27 \%$ of land area while protected areas in Sri Lanka. The lack of sufficient areas for the existence of elephants is the main reason for human-elephant conflict. Increases in human-elephant conflict also decrease the Elephant population in the country. Reducing forest development, the rape of forest, villagers, encroaching into the forest, grasslands being used by farmer's cattle, low forest quality is the main reason for the reduction of elephant population. "Between $30-50$ people and more than 150 elephants die annually in HEC. In addition, it has become a serious issue among Sri Lanka in the rural community (Fernando et al.; 2005).

Although the Island of Sri Lanka consists of elephants, four of them were found dead near the city of Habarana (according to SEPAL, except for one female, all the others are believed to have been poisoned (Anon; 1991).

Jayasundere (2010), asserts that the causes of an elephant's death are poisoning, electrocution, natural reasons such as starvation or scarcity of foods, and sickness. The major cause of elephant deaths is a gunshot. The most common reason is falling well and landmines. There is a record of elephant accidents. This is quite frequent in other parts of the country.

Elephants were risked in Northcentral province during the drought, when they jumped into the well, climb down to terete water flows which come from major tanks. The Sri Lanka population is now restricted to the dry zone in the northeast, southeast Sri Lanka.

Wild elephants are increasingly entering villages in search of food rampaging through houses, defrosting crops (Gunatilake, N;2008).

Between 1950 - 1970, 1,163 elephants were lost in the wild in Sri Lanka. 639 were killed by farmers to define their crops. We normally lose 32 elephants from all pesetas in Sri Lanka. The 2007 year alone, 133 elephants lost their lives of which 80 died of gunshots. Injuries, 19 were electrically shocked, 8 died by falling into wells (Anon;1991).

\section{Human deaths and injuries}

In the last year alone, the HEC resulted in the deaths of 76 humans killed by elephants. Statistic explains that there is no border ecological struggle to take place in post-war Sri Lanka.

"Elephant's ability to fight back their intelligence and cultural significance has given them a media spotlight. However, thousands of other species come into conflict with humans daily and deaths are less reported (DWC 2006 -2007).

\section{Electric fence.}

Electric fence is perceived to be the best solution for the human-elephant conflict, however, as many projects will testify. It is only with careful planning, costly construction, and commitment to maintenance. In combination with some other means of evicting or punishing tending elephants, several hundred kilometers of electric fences have been erected in Sri Lanka mainly along with national park boundaries. $600 \mathrm{~km}$ of fencing is planned to construct format Wilder life conservation unit. Most of the electric fence was made an ineffective fence for humans as well as elephants.100 elephants were driven into Lunguamevema National park palliated area in 2007.

Yala and Lunugamvehera have deployed elephants temporary fences using metal posts have been extensively used in 
conducting elephant driven to the problem elephants appear not to be easily detected rather it seems to make sense to identify their target and then to keep them out (Santipillai, C, Wijayamohan, S, Bandara, G,2018).

Local people should also be supported so that they can play a role in maintenance to present land-use patterns, habits. We need local people's property and perceptions of elephant threats. The D.W.C has currently deployed over 1200 $\mathrm{km}$ of the electric fence. Electric fence is arguably the most effective tool for preventing crop depredation by elephants (Fajardo;2000). Over $2500 \mathrm{~km}$ of the electric fence has been constructed by the Department of Wild Life Conservation for HEC mitigation. The majority of these fences were made in the boundary of protected areas.

The area adjacent is fresh land under the forest department, where also elephant consequent elephants were found in both sides of the village.

\section{Human-Elephant - Cultural Concepts.}

Elephants hold a central position in the country or maintain religion, Buddhism, Hinduism as well as Sri Lanka elephant has considered for a symbol or physical, mental, strength, intelligence, and responsibility. Number of Elephants are used by domine as the feature of temple annual peents as "peripherals". Most of the famous perahera was held in August in the city of Kandy, which featured up with a hindered richly caponised elephant fest one with lights together with thousands of crammers, musicians, dance main ceremonial elephant of the root relic of the Luard Buddha of a majestic tusker of highest caste (Fernando;2011).

Sri Lanka has a very close association with elephants that extends back millions. Many ancient treatises explained captive elephants have been identified as a caste" management characteristic. Elephant mafias have been widely used in Sri Lanka art since ancient times (Anon;1991).

Prominent carvings, sculptures, and many other examples can explain the history of captive elephants that were heavily utilized for labour war, religious and cultural activities (Jayewardene;1994).

The species is deeply embedded in human culture and literature. (Bruno 1931). Although it is not widely revered as the elephant is in Hinduism (Stacey, 1963) has rarely been tamed. Robert Knox, who has held prisons in Rajasingha period (1666-1697), refers to the damage caused by wild elephants to orchards and plantations (Anon;1991).

\section{Theoretical Framework.}

\section{Human-elephant conflict in political ecology}

Elephants are intelligent social animals and, as a keynote species, they support the survival of all other species in ecosystems. The elephant is also important for wildlife tourism, supporting the economy of many African countries. Not surprisingly, the decline of the elephant population in Africa has caught the attention of local regional and international states and Non-state actors (Chapman et al.; 1992).

(Gunatilake:2008) investigates attitudes towards the elephants among the Kamba, who live around Chula Hills National park, and the Kasugai taiga people using the lens of political ecology. Political ecologists ask what we consider events as a part of the historical and social process, including the relationship between human-wildlife (Blaikie;1985, Neuman;1992).

The global perceptions that tend to idealize that African elephants are often in slow contrasts with local perceptions of elephants, people who live in villages next to protected areas encounter elephants in their day-to-day lives. Options are based on their historical and current experiences. Elephants destroy crops the present farmers depend on for survival, they also injure and kill people. Elephant with their size, capacity, hunger, mobility, determination, and complex international humanitarian and conservation concerns, through economics, to crop-raiding at night is at smallholder's farms is an obvious target for geographers interested in animal agency. The history of interaction between elephants and people is long and their signature on human culture is deep (Anon;1991).

Traces of elephants "litter histories and geography of civilization and everyday lives" (throne; 2000). Those relations have never been simple, Asian elephants have been subjected to hunting, captivity, ecotourism, and scientific research in Sri Lanka have been embedded in human networks of concern (Anon;1991).

Elephant, perhaps most clearly located as an actor in conservation politics in two ways. The First elephant lives outside protected areas in patrol and agricultural landscapes, shared with people. Many landscapes have changed progressively as human land use has intensified. Human-elephant conflict is a mute and stable background to the actual business of politics (Hinchcliffe; 2008). Some actors shape politics both alone and through co-production with human actors (Jepson,et. al;2011).

Human-Elephant Conflict-Livelihood Environmentalism.

Environmentalism explains the grassroots level of environmental protection with philosophy, ideology, and social dimension, particularly concept explaining the environmental protection and improvement of environmental health. Incorporate the impact of changes to the environment by human animals and plants. It was a focus on the nature-related aspects of green ideology and politics, ecology, and social ecology.

Livelihood is means of making a living. It encompasses people's capabilities, access, income, and activities required to secure the necessities of life. Livelihood was as sustainable to people to cope with the recovered stress and it was a helping hand to get good wellbeing for their life.

Sustainable devotes a sense of endurance and resilience to shock and stress. Sustainable livelihoods may be secured through the ability of subsistence farmers to sufficiently protect their crops from elephants and cultivate crops less frightened of HEC.

Sri Lanka has the highest level of human-elephant conflict in the world. An average of 250 elephants and 70 women lose their lives annually due to HEC. Farmers in the affected areas lose approximately $6 \%$ of their cumulative annual income due to crop destruction. The concept of irrational to believe that HEC encounters were completely absent throughout the Sri Lanka long civilization, intense in the conflict, appears to be a recent development that has intensified into crops (OswinPerera;2002).

An Elephant can eat $450 \mathrm{~kg}$ of food per day. They are messy eaters, uprooting and scattering as much as eating. Small farmers, often desperately poor, already economically and nutritionally vulnerable livelihoods in overnight from elephant rights.

"Reducing habits and the human-elephant conflicts records the deaths of both humans as well as elephant the greatest threat in Sri Lanka" (Biodiversity and Elephant Conservation Trust; 2011)

The study was conducted to assess the extent of damage caused by elephants in Polonnaruwa district. The main of 
this study is to explain the human-elephant conflict under the present context, how it negatively impacts farmers' livelihood and agriculture.

\section{MATERIAL AND METHODS}

\section{Data Collection}

The present study relies on the systematic review of existing literature and empirical findings. Exploiting search strategies, research articles, journals, newspaper articles, Department of wildlife conservation reports were used as primary and secondary sources to identify the concepts of Human elephant conflict and the challenges faced by agriculture and farming and elephant mortality. Official Government News Portal of Sri Lanka (2009), Primary report on the small farm sector, Polonnaruwa district (2013-2014), Economic Census and Performance report of wildlife conservation (20062007), and other related sources. Despite, following antecedent studies, henceforth criteria were harnessed to choose the materials.

\section{Research Area (Polonnaruwa Significant of the Study)}

Polonnaruwa is the most significant area for HEC. Researchers have selected Polonnaruwa district in the North-Central Province in Sri Lanka. However, HEC is a long-term phenomenon in Polonnaruwa. It has become a serious problem for the social, economic, and conservational problems in Pol- onnaruwa. Therefore, more important to determine the reasons and present negative impact for a governmental local authority. Polonnaruwa has 1,333 sq km forest cover and 200 minor resources. Kaduruwela, Medirigiriya Minneriya, Bahamian, Grit ale, Jayanthipura, Galamuna, Lankapura, Manapitya, Hingurakgoda are main divisions of Polonnaruwa. Coconut $56 \%$ of the area under agriculture holdings. The agriculture census says $5.5 \%$ of paddy is extended on the Island (DWC;2006-2007).

Wildlife authorities explored that there was a dramatic rise in human-elephant conflict and over 70 elephants had stormed into this area of Polonnaruwa. (DWC;2006 -2007) survey points out 881 elephants, this pollution has reduced Polonnaruwa Matale, Ampara due to people's behaviour and caught the elephant habitats by villagers.

Farmers kill elephants. 225 elephants have been killed by farmers in Polonnaruwa district. The families are affected by the threat of wild elephants. Around 25,000 of the family's livelihoods are based on agriculture and harvest. Due to the destruction, there was an enabled tendency in the harvest.in addition, it has been highly affecting child education in Polonnaruwa. The Polonnaruwa wildlife zone has increased in an alarming proportion and 31 elephants were killed and 5 villagers injured during de HEC in 2019. (Samantha Linage;2012)

The above statements were proven the threat of human-elephant conflict in Polonnaruwa district.

Figure2 Map of Polonnaruwa.

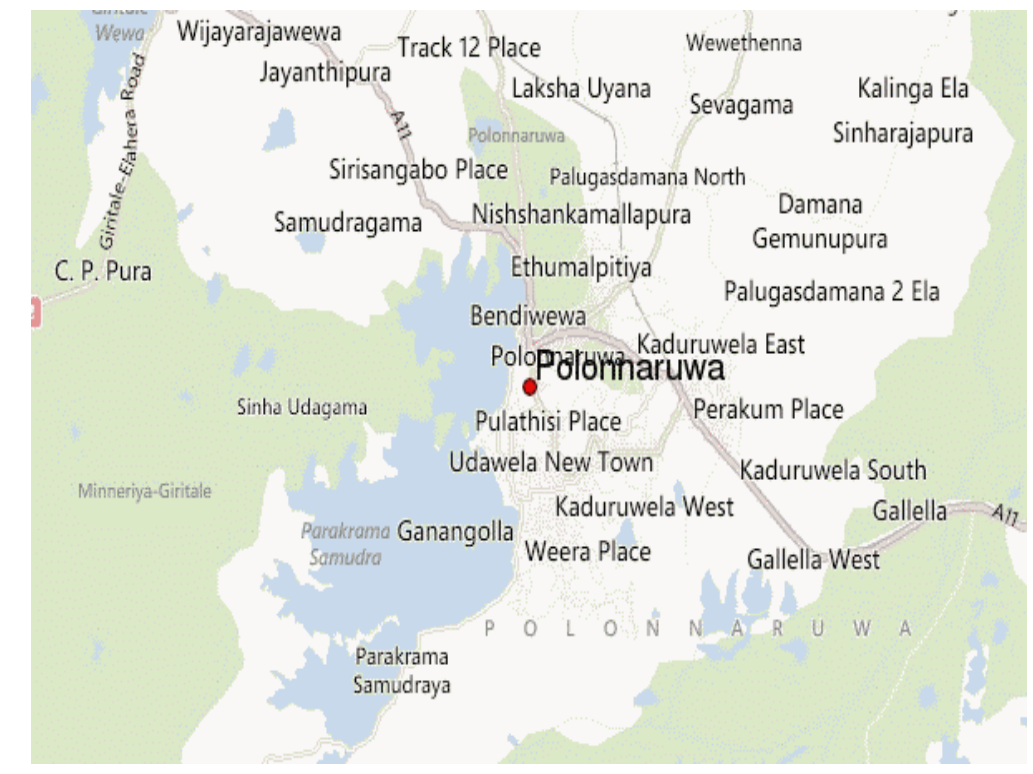

Source:

\section{RESULTS AND DISCUSSION}

\section{Reasons for Human-Elephant conflict in Pol- onnaruwa.}

The human-Elephant conflict has increased in Polonnaruwa due to various factors. According to the findings, $72 \%$ of people pointed out that elephants are major problematical wild animals rather than other animals. Also, monkeys, peacocks, wild boar, rabbits are causing damage to crops

Castaldo Walsh, C. (2019). It is essential to identify and understand the root cause of the problem. Most of the farmers were deployed first reason is the encroachment of elephant habitats by people. Most of the farmers' land was very much close to Somawathiya park. $22 \%$ of people out that elephant come to the village due to destruction of elephant's corridors. Clearing the forest cover for human settlements, constructing roads, and forest development projects increased the problem.

Figure 2 shows that prominent reasons for human-elephant conflict are, elephants find food in drought season, due to lack of food in the forest, destructing elephant corridors, encroachment of elephant habit is HEC in Polonnaruwa. 
Figure-3 Reasons for Hunan Elephant conflict.

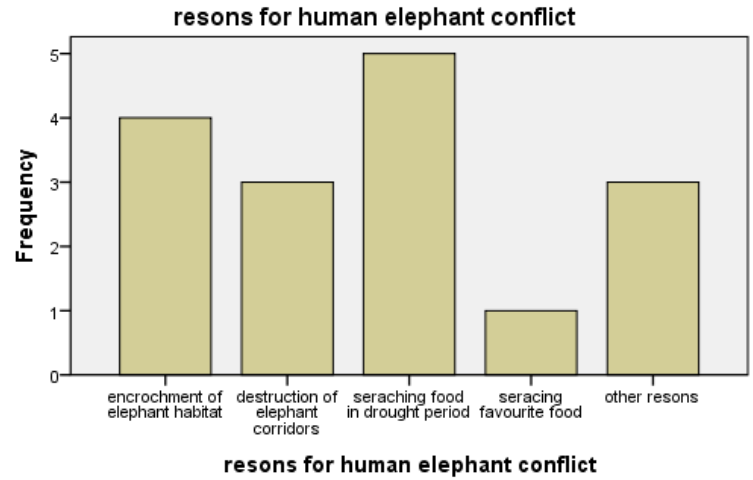

Source; (Gunawardhna; 2018).

(Charles Santiapillai1;2010), Pangurana village was $0.5 \mathrm{~km}$ away from Kawdulla wewa. Most farmers explain that elephant arrival is very high in the dry season. Specially in drought (Gunawardhana; 2018). Wasgamuva National Park is the main water and food resource for elephants, but it is also used by villagers living next to the forest.

\section{Elephant induced damage on humans: crop dam-}

\section{age}

Although the contribution of agriculture has declined to $6.9 \%$ national GPD, nearly one-third of the population of Sri Lanka depends on agriculture and livelihoods (Central Bank Report; 2017). Rice is the staple food of Sri Lanka. This paddy cultivation receives the highest attention in agriculture. Apart from this, other seasonal crops such as Maize, Sorghum, vegetables, coconut, and banana are among the most grown crops in Polonnaruwa. These crops will cultivate in home gardens and other highland plots. (Santi Pillai, et al.; 2010).

An elephant is causing several damages to farmers by the destructing of crops, property, and human casualty most of the time damage crops such as rice, banana, coconut, corn, and much other small agriculture. $40 \%$ of people agreed that crop damage is the highest damage by the elephant. It was clear in the field since 15 days from the commencement of cultivation of the above crops are being destructed. The Possibility we could see damage has occurred in several stages of agriculture.
1. vegetative stage

2. Reproductive stage

3. Formative stage

To prove the incidents could be seen that wild elephants have completely and partially destructed the paddy. Almost $90 \%$ of paddy has been destroyed due to elephant arrival (L.H.P Gunarathne, P.K Premarathne; 2005).

- Seeds were destructed on the very first day of planting-15\%

- Crushing of tender plant during the germination period-21\%

- Crushing of tender plants and mature plants $-40 \%$ According to Prithiviraj Fernando, Jayantha Jayewardene, Tharaka Prasad, W. Hendavitharana; 2011, banana cultivation is the main argument that could be seen destroyed during germination period. Approximately $72 \%$ of paddy fields, Banana plants in the area are destroyed, $35 \%$ of Banana crushed in tender plants, $72 \%$ of trees are destroyed when it is grown trees. $75 \%$ of rice, Banana, Coconuts trees have been destroyed. The destruction caused by wild animals to China cultivation into consideration the damage is prominent and high in rooted crops such as peanuts, beetroot, which are growing in Yala season. Mediriyagoda division area around 68 acres destroyed by elephants. The total number of banana trees planted in this out of $75 \%$ land has been crushed and damaged. Altogether, $82 \%$ of paddy fields were destroyed in 2009.

Table-01 Data about type of cultivation and percentage of damage from HEC

\begin{tabular}{lll}
\hline Responders & Type of cultivation & Damage to the cultivation \\
\hline 01 & Rice, Banana, & $72 \%$ \\
02 & Rice, Coconut, Banana & $62 \%$ \\
03 & Banana, Coconut & $54 \%$ \\
04 & Rice, Banana, coconut & $65 \%$ \\
05 & Rice, Banana & $69 \%$ \\
06 & Rice & $80 \%$ \\
07 & Rice, Banana, Coconut & $75 \%$ \\
08 & Banana, Coconut & $82 \%$ \\
09 & Rice, Banana, Coconut & $80 \%$ \\
10 & Rice & $95 \%$ \\
\hline
\end{tabular}

Source: 
Figure -4 Total Number of cultivation damages. Source; (Fernando; 2011).

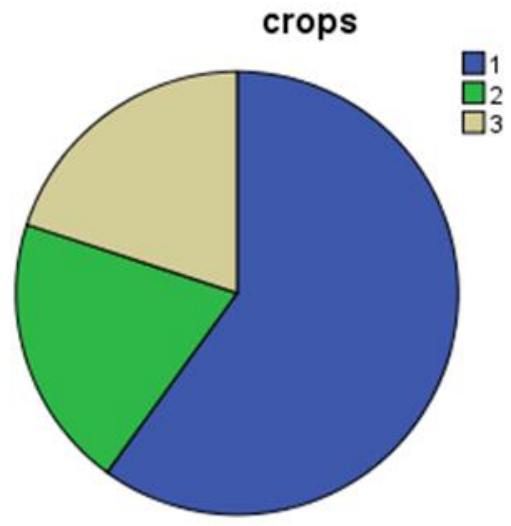

Source:

(Sunterra Thennakoon,Thisara Kandamibige L.S; 2017) explored that elephants arrival to village, $32 \%$ responders agreed that there is no special month, or season elephant, always elephant can be seen in this area. Most of the area accepted that elephant comes in the Yala season (April, May June) and Maha season (September, October, November). $80 \%$ of responders say elephants will come in a drought period search of water and food especially in September, October.

In addition, $72 \%$ of the responders agreed the elephant comes at the night-time

(After $9.00 \mathrm{pm}$ ). $32 \%$ of responders agreed $4-5 \mathrm{pm}$ is the arrival time (Wickramasinghe; 2017).

Elephants attack the ruler farmer's livelihood, especially large groups of elephants that can destroy wider areas of crops in a single night. Furthermore, they were attacked on cash crops such as Bana, Coconut (Charles Santiapillai1;2010).

The review illustrates that crop damage, agriculture destructions are highly increased due to human-elephant conflict.

\section{Economic loss for Farmers.}

Previous studies illustrate that the main income source is farming. Besides farming people also generate income from other enterprisers livestock, paddy. Although the principle of crop damage by an elephant is assessing the direct economic loss for Polonnaruwa farmers. There are other additional indirect costs incurred due to the need for people to spend a sleepless night trying to chase elephants from the village. The main economic damage is hunted by elephants in the agricultural areas. The survey was destruction crops, although other wildlife species such as parrots, peacocks, wild boar, and elephants were most widely feared because of their ability to eat and trample large quantities (Charles Santiapillai; 2010).

The majority (89\%) of the farming families appear to earn leases than the rest. 120000 per year. Only $10 \%$ of the farmers do an annual income range between 12000 and 40000, while only $1 \%$ of farmers earn 24000 thousand. The poorest $45 \%$ earn less than 50000 for a month. Losses are a concern to $25 \%$ and $32 \%$ are between 5000 and 0000 for the year. The estimation of economic losses that arise due to HEC is complicated in Polonnaruwa, including the destruction of crops by elephants and other indirect costs like the effort of people to chase animals are difficult. Sometimes, crop losses arise because of trampling. In others, they feed on the crops. All of them have their farmland and $45 \%$ of farmers' land between 1-3 acres.
Total Number of cultivation damages.

- Paddy $-90 \%$

- Banana $-72 \%$

- Coconut-55\%

\section{Non - Agricultural damage. Property and house damage.}

Besides damages to cultivation, other damages caused by wild elephants were identified during the Yale and Maha season. Once the harvesting season is over, elephants enter home gardens and destroy the cultivation.

elephants cause major damage in the harvest season and when the harvest season is over, elephants come and damage their homes.

According to the (DWC; 2006 -2007), all farmers agree during the paddy season, house damage and property damages are very less. There is huge damage after the harvest.

House damage depends on several factors. Location of the houses close to elephant corridor making construction houses grain stored insight houses. Nearly $82 \%$ of responders agreed with their houses. Depends on the above factors and water resources very close to their residence.

Property damage is done by a wild elephant can be deveined into 03 or more categories.

1. Wall cracks

2. Collapse, rood breakage

3. Doors and windows

4. Grill breakages

$13 \%$ of farmers agree on door and window breakage and $19 \%$ while grilling breakage $8.3 \%$ of people's furniture destroyed in their households.

Most of the farmers keep grain in their houses. Crops are grown in home gardens elephant brow ten houses and 81\% of temporary houses were broken by the elephants when came to seeking foods. According to our findings, studies show people's interpretations of how they face challenges.

"It is too sure elephants are coming daily. Further had planted more than 40 banana trees near the house. Last Tuesday we heard some peculiar noises went to see the land. Only I and my daughter were at home. 4 elephants came and fully destroyed the whole banana plantation. We could hear the sound.

Responder 03-"It runs on the wall. The wall did not collapse. It runs on to the window and breaks it took. Away paddy was eaten......" (Samatha Linage;2012).

Most research explains house damage accounted for $10.9 \%$ of HEC incidents ( 118 houses were attacked), elephants attacked due to consuming food, and drinking water deposits (Home water). several houses suffered from (49.2\%). Frequent for clay houses $(52.8 \%)$ than cement $(14.2 \%)$ other 
metrical although elephants attacked houses more frequently when no person is inside. (68.6\%) (Fernando et al.;2011).

\section{Elephant deaths as well as human deaths and inju-} ries in Polonnaruwa due to Human-Elephant con-

flict.

Human death and injury.

DWC explains above $60 \%$ of elephants were killed in Polonnaruwa district, including 8 divisions, and over $52 \%$ of people were injured and hospitalized due to the elephant attack. Nearly 05 men, 02 women were killed by an elephant attack this year (Sunetrra Thennakoon, Thisara Kandamibige L.S;2017).
Inspector deploys nearly 3 or 4 farmers got injured by elephant attacks and they lost their legs and are termed as disabilities. When we analyse the perception of human life, $70 \%$ of farmers are scared to live in this area, because of financial-economic purpose only they are here. Most of the farmers agreed that there are large man injuries in this area. (Burke, J;2011).

Many death is caused by the irresponsible behaviour of the public, such as approaching wild elephants while harassing elephants and unnecessarily chasing them. Researchers found an annual elephant death rate of 263 in 2010 -2019 in Polonnaruwa district, and also 9 humans died due to HEC. Typically, 3-5 people are injured monthly due to elephant attacks. (Wickramasinghe, $\mathrm{K}$;2017).

The number of Human deaths and elephant deaths combined was highest in north-central

Figure-4 Source-(Anon; 1991).

\section{Human Deaths Caused By Wild Eleplants}

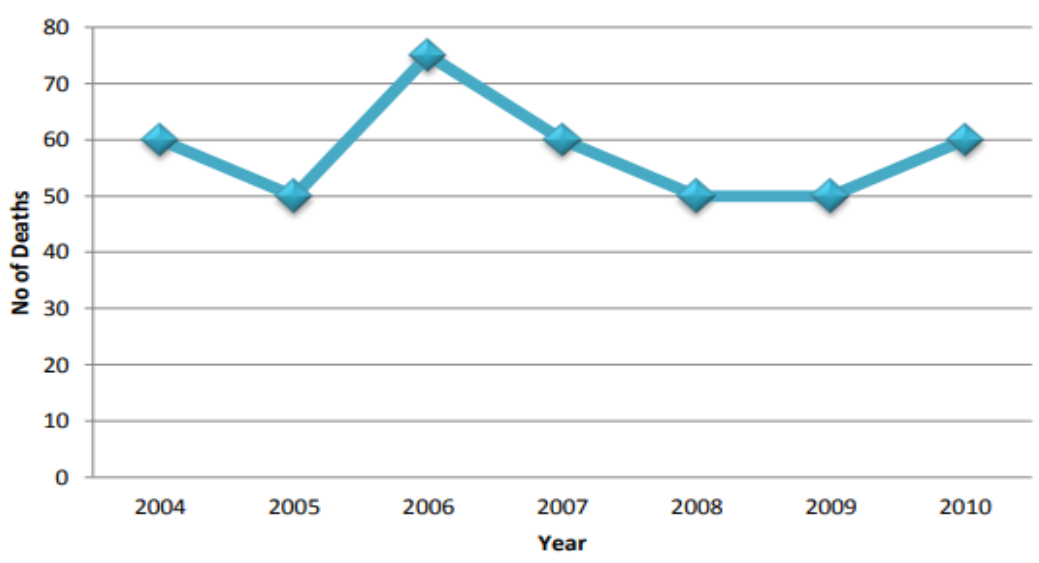

Source:

The figure- 5 shows a high range of the human deaths caused by HEC in 2006. In addition, 60 deaths in 2004 as well as 50 deaths in 2008,2009. (Anon;1991).

\section{Elephant morality in Polonnaruwa.}

The Human Elephant conflict in Polonnaruwa has frequently increased in an alarming proportion each year. According to the Polonnaruva district statistic of wildlife, conservators said 31 wild elephants in the Polonnaruva had died due to
HEC in 2019. Figure 6 shows that the highest range of elephant deaths occurred in north-central province. In addition gunshots, accidents are prominent reasons for elephant deaths.

Polonnaruwa is a UNESCO World Heritage Site, which is about 80 miles from South Horowpothana. This is also the largest Number of elephant death reported areas.

Figure; 5 Reasons for Elephant death. Source ;( DWC 2006-2007).
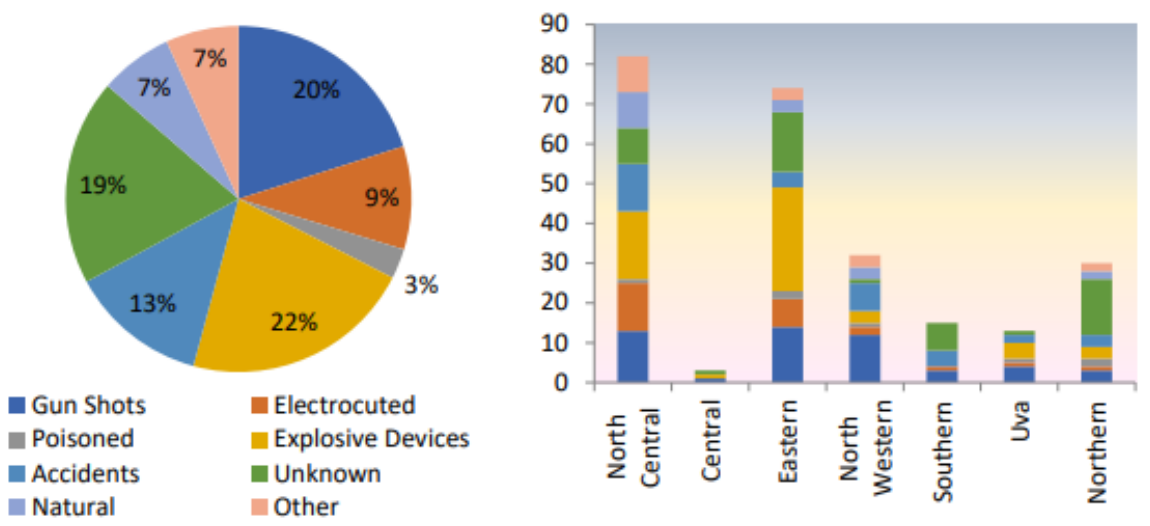
(Charles Santiapillai; 2010) explained 5 villagers had been killed by wild elephants and at the same time 76 wild elephants had died due to the HEC. He explored the death of wild elephants and villagers in the past 4 months of this year has increased when compared to the previous year. The opinion of the illegal clearing of the forest is the main cause of HEC in Polonnaruwa.DWC;2006 -2007 Statistical data explain that most of the wild elephants had been killed by laying traps, a locally made explosive device was "Hakka Pattas" by shooting. The highest number of attacks was reported in April, May, and October. Owing to the high frequency of elephant migrates that occur during the northeast and southwest monsoons by increasing human-Elephant confrontation in Polonnaruwa.

Table - 2 Annual Number of Death of Elephant (frequency of Annual Number of Death)

\begin{tabular}{llllll}
\hline Wildlife Region & 2014 & 2015 & 2016 & 2017 & 2018 \\
Polonnaruwa & 57 & 37 & 54 & 47 & 76 \\
\hline
\end{tabular}

Source; (Distribution of wildlife region Polonnaruwa 2014-2015)

Table 2 illustrates that 76 elephants deaths occurred in 2018 , it has been identified as a high range of elephants died during this year. According to (Ranjithkumar; 2011).to the findings, elephant morality is very low at the present. Nearly $60 \%$ of elephants were killed by farmers due to the humanelephant conflict. Farmers use local mitigation methods to control the situation. Most of the time, it will reflect on elephants. Often farmers use firecrackers using pointed fruits. Covering this land area of $2000 \mathrm{~km}^{2}$ and comprising around 05 villages showed that there were $50-100$ elephants in this area.

\section{Local common mitigation methods used in Pol- onnaruwa.}

Animal explores the only effective solution was to continue to erase the fences system with the support of villagers in Polonnaruwa. Cutting fences should be used to protect the settlements and crops, hence they should be constructed at the boundaries. A similar electric fence has been deployed by government and non-government organizations. $30 \%$ of fences have been deployed near the Somawathi Natural Park, Kawdulu Tank.

The farmers' most commonly used preventive measures are the making of fires around the field.

( $75 \%$ farmers used). Although most of the farmers agreed to shout when they notice an elephant comes (20\%), whistles or although banging on the tins and drums (15\%). Using flashlights to chase the elephant back in the forest. Most of the farmers explain they used chili powder. (52\%)

(Mixing chili on manure and setting it on fire and creating repelling smoke) and also they mentioned smeared on fence ropes on the field.) The global wild elephant is present in 50 countries. 130 which are in Asia and 37 in Africa. At the present, the number of wild Asian elephants is between 35,000 $-50,000$ while the number of captivity is around 10,000 (Burke, J; 2011). At present, human-Elephant conflict has highly increased nationally and globally. These conflict rates are increasing as the landscape continues to be transformed. Fewer amount resources are left for wildlife. Local communities are affected by these conflicts. Researchers have released/stated 160 elephants and 60 people die each year due to human-elephant conflict. As per the Previous reports number of human death were 51 and injuries 33 from 2009 to 2010. The Number of property destruction is 752 . These conflicts are still growing in our country without a proper solution.

Globally, 15 African countries explore the physical and social factors that highly impact farmers' lifestyles due to humanelephant conflict. Sri Lanka boasts and/the elephant's population is more than 7500. Although 80-100 human deaths are recorded early pawing at the human-elephant conflict. Statistic proves the most human deaths caused by wilder elephant attacks are taken place in Polonnaruwa, Eastern, Anuradhapura, southern, Northwestern, Uva wilder life zones (Shanmugaraja Vijayamohan, Rukmali;2012).

Elephant conflict daily gambled with life and death. The Environmentalist's point of our Human-Elephant conflict has increased more in our society. Death and property damages are a much-rooted issue. This issue has created a considerable impact on the rural livelihood economy of Sri Lanka as well as the national economy (Gunatileke, N; 2008). Increasing human activities in forests and elephant survival is a major threat to elephants.

The Number of families' livelihoods are based on agricultural activities (DWC; 2006 -2007). Although many other social issues are arising through human-elephant conflicts, such as poverty. Poverty is caused by the destruction of harvest by wilder elephants is an obstacle to national development. And also has a negative impact on the education of the area where this issue exists.

The study was conducted to assess the extent of damage caused by elephants in the Polonnaruwa district. The main of this study is to explain the human-elephant conflict under the present context, how it negatively impacts farmers' livelihood and agriculture.

Table-3 Results in the mitigation method.

\begin{tabular}{lc}
\hline Common mitigation methods & Responses in percentage \\
\hline Shouting & 20 \\
Kerosene torch & 10 \\
Banging tins and drums & 15 \\
Born fires & 10 \\
Scarecrows & 34 \\
Through stones and chili & 52 \\
Firecrackers & 75 \\
\hline
\end{tabular}

(Source; DWC 2006- 2007) 


\section{Bio fence made by farmers}

Farmers have explained that for trespassing elephants, they have cultivated lemon and medicine plants like Malabar nut (adhathodvasica), pawatta (adhathoda)in their village border. These plants help to earn a small income while repelling elephants (B.M.A Oswin Perera;2002).

\section{Measures are taken from government}

Most of them are agreed that the government has established a construct of an electric fence in between forest border and village. But anyhow elephant breaks the fence entering the village. However, these methods are only effective when it is used in combination and more people are effective with this mitigation. $77 \%$ of responders said this crop guarding keeps away the animals to a certain extent. Poor effectiveness of mitigation methods will provide more danger, $54 \%$ of the respondents also said the crop-raiding still occurred despite crops being guarded (Abdeen. J.S. M, 2008)

"Electric fence insight forest area is very difficult to maintain. After a couple of years, construction becomes dysfunctional. Electric fence is one of the psychological barriers for elephants. Once elephants learn to break them, the fence becomes less useful. This construction is sole to protect the farmer's cultivation (Anon;1991).

\section{Compensation for farmers in Polonnaruwa.}

The study focuses on identifying a few aspects of HEC. I explore how compensation was prevailing among farmers due to HEC with their experience. According to Abdeen. J.S.M, $(2008$,$) analysis we can explore that 77.5 \%$ felt that compensation for necessarily those who have experienced crop and property damage, human seat and injury. Damage composition will be provided by the particular area Wildlife department. The department had paid a sum of rest 8.8 million for human deaths Rs.1 million as compensation for injuries, 22.2 million for crop damage (Burke, J;2011).

Normally, compensation will provide after death for at least 8 months and often over a year. According to the new parliament, the plan can be underway shortened to 3 months after death (Oswin Perera (B.M.A;2002).

Low compensation for farmers due to the elephant damage in Polonnaruwa.
Farmers were getting low compensation for their damage. Previous secondary research explores poverty with a loan. $76 \%$ of responders agreed that there are involved in an insurance and compensation scheme to get compensation after the attack. The majority of farmers have been involved in Sri Lanka insurance, calico insurance, and much other insurance cooperation, including state for their land and life. Rural farmers' participation has a dependency on economic loss. The majority of farmers had experienced economic damage in the last five years. Farmers were more willing to contribute funds to the scheme (Abdeen. J.S.M;2008).

HEC affected farming families in Sri Lanka with a total of 327,840 rupees and 20.06 million per month, 240.72 per year. This would be generated at 1194.62 million with 5\% interest.

(Their entire farmer contributions were invested in the capital market. Six selected leading insurance companies conclude their compensation scheme for farmers, although government organizations may also have included. Most of the farmers explain the amount of compensation depends on their damage. The Compensation amount will provide after the wildlife inspector's confirmation, police investigation.

\section{Electric fence}

Animals explore only effective solution was to continue to erase fence system with the support of villagers in Polonnaruwa. That cutting fences should be used to protect the settlements and crops, hence they should be constructed at the boundaries. Similarly, the electric fence has been deployed by government and non-government organizations. 30 fences have been deployed near the Somawathi Natural Park, Kawdulu Tank.

Nearly 20 households were benefited from electric fences. These fences were supplied by the government with funding from the DWC programme. These fences were then handed over to the people for maintenance, which was usually done on a rotational basis group of male elephants break fences $45 \%$ of fences were damaged by elephant attack last year (Jaiteh Samantha Linage;2012).

(Gunatilake, N;2008) study says that new electric fences were erected in Portugal Vihar, Parakramasamudraya, Thibalawa, Hiru Vaduna areas in Polonnaruwa.

Table - 5 New Electric fences erected in 2019

\begin{tabular}{llc}
\hline Elephant Region & Name of the electric fence & Length \\
\hline \multirow{2}{*}{ Polonnaruwa } & Portugal Vehar & 5 \\
& Parakiramasamudraya & 12 \\
& Thibalawa & 8 \\
& Hiru Vaduna & 2 \\
\hline
\end{tabular}

Source - (Central Environmental Authority; 2018)

\section{CONCLUSION}

This study mainly reviews on given details about the extent of the damage caused by elephants to human crops and property, although describing the elephant morality at present in Polonnaruwa district. Human-elephant conflict in Polonnaruwa's rural livelihood is a risk due to human-elephant conflict. The main livelihood of $90 \%$ of the people in this area engaged in agriculture as their main occupation. Elephants caused serve damage to agriculture. The main reason for this could be the increasing population and people's needs. Since both species require large areas. Agriculture in- cluded depletion of elephant's habitats in the dry zone, owning OD small-farmer agriculture expansion. Is among the most critical and ongoing drivers. Behind this conflict.

Annually, elephants cause over 10 million crops and property damage and in retaliation, the farmer can kill the animals. Over 22 elephants have been killed since 2008 (Burke J; 2011).

Elephants for their food and water, humans through settlements and cultivation. The damage was high when the distance is more home to the cultivation area. If the distance is less, we could see the damage was less. Most of the damages are done by cultivation land situated close elephant border. (Pangurana away from Somawathiya park) Finally, 
increasing human activities taking place in the Human-elephant conflict range (Prithviraj Fernando; 2011).

Wildlife inspectors, explain Sri Lanka elephant morality, especially in Polonnaruwa district, the elephant mortality rate has been decreased since 2005. Because farmers have been ignored or beyond to reach of the elephants. Each year almost 20-30 elephant killings are due to human-elephant conflicts. Local mitigation methods and electric fences were increasing elephant deaths (Vincent R, Miranda, Bio A.Nkhatha;2018).

Total 28 elephants conflicted. Elephant mortality was decreased in Northcentral province. The west majority of elephants reported killed in the conflict by gunshot (Anon;1991).

In-country where conservation, social-economic needs of their rural people have equal priority and impact and will produce both farmers live hoods and conservational efforts.

To prevent human-elephant conflict, first better to use planning, which can be used to avoid settlements and cultivations close to the protected area. Since the people were living very close to the border. They would force to move into the buffer zones. Therefore, mitigation through preventive and deterrent methods. The government declared electricity fences and physical barriers. It should cover the farmers' land and the entire village. Although government or responsible authorities have to maintain a proper compensation method there to reduce the economic loss. Farmers are very much poor to re-develop their cultivation after the attack. The government may have long progressed in providing compensation, most of the time it could be familiar. Further, maintaining a positive idea on elephant attitude, conservation methods for elephants increasing tolerance for farmers (insurance scheme, performance payment) for such reason would be an important concept to reduce human-elephant conflict from the society.

\section{Recommendations}

Researches should be enhanced in other areas in Sri Lanka. Effective conflict mitigation methods have to follow in a proper way to reduce the conflict for the long-term implementation. The capture and translocation of elephants, a distribution survey elephant census, GPS collaring of elephants, improving electric fence designing are also required as effective mitigation methods. Government and non-government organizations have taken considerable efforts in reducing human-elephant conflict.

Authorities say have to develop elephant tracking data mechanisms to minimize human-elephant conflict by shedding light on the animal's movements and identifying areas not often visited by elephants for the development of agriculture. Mitigation of HEC needs a carefully planned series of actions and may take a long time. It is essential to educate the villagers and farmers concerning the human-elephant conflict. Most were in the low dry zone, where human pressure was not serious enough to prevent the recovery of the number of elephants. Development activities are planned on a landscape or ecosystem level, with the involvement of all stakeholders taking proper precautions to understand elephants work around them. Enhancement stringent laws, which are currently provided by authorities. Many farmers affected by HEC belong to the low-income category, payment of insurance premiums is a significant economic burden for them. To reduce such circumstances, have to be created popularizing insurance schemes to mitigate the challenges.

\section{REFERENCES}

Alastair, N., Claudio, S.(2003). Review of human-elephant conflict management. Retrievedfromhttps://www.researchgate.net/publication/253425249_A_review_of_human-elephant_conflict_management_strategies.

Anon. (1991). Natural Resources of Sri Lanka: Conditions and Trends. A USAID sponsored report for the Natural Resources, Energy, and Science Authority of Sri Lanka. Colombo.

Abdeen. J.S.M, (2008, Aug 24). Call to protect elephants, Sunday Observer national newspaper Sri Lanka. Retrieved From http://www.sundayobserver.lk/2008/08/24/new15.asp. (Accessed 2020/05/16).

Burke, J. (2011). Sri Lankan wildlife activists boycott wild elephant census. $\quad$ Retrieved $\quad$ From http://www.guardian.co.uk/world/2011/aug/10/sri-lanka-boycott-elephant-census, (Accessed 2020.5.20).

Castaldo Walsh, C. (2019). Human-Wildlife Conflict and Coexistence in a More-than-Human World: A Multiple Case Study Exploring the Human-Elephant-Conservation Nexus in Namibia and Sri Lanka. Doctoral dissertation. Nova South Eastern University. Retrieved from NSU Works, College of Arts, Humanities and Social Sciences-Department of Conflict Resolution Studies. (134) https://nsuworks.nova.edu/shss_dcar_etd/134

Colombo Page, (2007). Rs 10 Billion needs to manage the elephants in Sri Lanka, Sri Lankan Internet newspaper, Retrieved From http://www.colombopage.com/archive_07/August31134754SL.html (Accessed 2020.05.06).

Department of wildlife conversations, (2006). National elephant conservation policy. Retrieved From http://203.143.23.34/index.php/policies-a-legislations/national-elephantconservation-policy.html?showall=1, (Accessed 2012/04/28).

Gunatileke, N. (2008, April 2). Alarming rise in Elephant deaths, The Daily News (Sri Lanka), 2008. (Accessed on 2020.5.18).

Lauren A .E., Madams, W. (2003). Elephants as actors in the political ecology of human-elephant conflict. Journal of Political science, Retrieved From https://www.researchgate.net/publication/322288188.

L.H.P Gunarathne, Premarathne, P.K. (2005). The effectiveness of electric fencing in mitigating Human-elephant conflict in Sri Lanka (Department of Agriculture and economic business management, Faculty of Agriculture, University of Peradeniya).

Nyirenda, Vincent R.; Nkhata, Bimo A.; Tembo, Oscar; Siamundele, Susan. (2018). Elephant Crop Damage: Subsistence Farmers' Social Vulnerability, Livelihood Sustainability, and Elephant Conservation" Sustainability 10, no. 10: 3572. https://doi.org/10.3390/su10103572

Official Government News Portal of Sri Lanka. (2009). Elephant conservation to be improved. Press Release, Retrieved From http://elephantssrilanka.blogspot.com. (Accessed 2020.05.06).

The official website of the Department of Census and Statistics. (2009), Agricultural Activities of GN Division level, Retrieved From http://www.statistics.gov.lk/Agriculture/Staticallnformation/new/EconomicCensus2013-14-AgricuturalEnumeration-BasicReports-PolonnaruwaDistrict. (Accessed 2020.05.06).

Oswin Perera, B.M.A. (2002). The Human-Elephant Conflict, A Review of current status and mitigation method, Faculty of Veterinary Medicine \& Animal Science, University of Peradeniya.

Praksh, S. L., Wijerathne, A.W., Supun T. G., (2020). Human-Elephant conflict in Sri Lanka; Patterns and extent. Biodiversity conservation research circle in Sri Lanka. Retrieved From https://www.researchgate.net/publication/341150414_Human-Elephant_Conflict_in_Sri_Lanka_Patterns_and_Extent

Performance report on wildlife conservation (DWC 2017). Retrieved From https://www.parliament.lk/uploads/documents/paperspresented/performance-report-department-of-wildlife-conservation2017.pdf. (Accessed on 2020.5.23)

Prithviraj Fernando1, Jayantha Jayewardene2, Tharaka Prasad3, W. Hendavitharana4 (2011), the current status of Asian Elephants in Sri Lanka. Current Status of Asian Elephants in Sri Lanka

Preliminary Report on Small Farm Sector, (2014). Polonnaruwa District, Economic Census 2013/14. Retrieved From http://www.statistics.gov.lk/Agriculture/Staticallnformation/new/EconomicCensus2013-14-AgricuturalEnumeration-BasicReports-PolonnaruwaDistrict (Accessed on 2020.5.21) 
Samantha Linage, J. (2012). "Master thesis in development management centre studies, faculty of economics and social sciences", University of Adger.

Santiapillai, C., Wijeyamohan, S., Bandara, G., Athurupana, R., Dissanayake, N. and Read, B., 2010. An assessment of the human-elephant conflict in Sri Lanka. Ceylon Journal of Science (Biological Sciences), 39(1) pp.21-33. DOI: http://doi.org/10.4038/cjsbs.v39i1.2350

Thennakoon, S., Kandamibige, L.S., (2017). Impact of human-elephant conflict on livelihood; A case study from a rural place in Sri Lanka.

Thennakoon., Sunethra Sathsara, K.L., \& Liyanage, C., (2017).Impact of Human-Elephant conflict on livelihood: A case study from a rural setting of Sri Lanka, International Journal of Applied Research and Studies, Retrieved From https://www.researchgate.net/publication/327034007_Impact_of_human_Elephant_conflict_on_livelihood_A_case_study_from_a_rural_setting_of_Sri_Lanka

Wickramansinghe, K. (2017, September 6). Mahiyangana's human-elephant conflict shows cracks in cultures of habitat, Retrieved From http://www.dailymirror.lk/print/news-features/Mahiyangana-s-human-elephant-conflict-shows-cracks-in-cultures-of-habitat/131136022 (Accessed on 2020.5.18).

World Wildlife Fund, (2008), Humans and Elephants on a collision course in south Asia, URL, http://elephantssrilanka.blogspot.com/search/label/wild\%20elephants, (Accessed 2012/05/17) 